\title{
Healthcare System Restructuring in New Zealand: problems and proposed solutions
}

\author{
R Gauld
}

\section{Abstract}

New Zealand's healthcare system is, like most, in a continual process of restructuring and change. While the country has endured several major system-wide changes in recent decades, more recent change has been incremental and evolutionary. Current changes are in response to a set of challenges, which are not unique to New Zealand. This article overviews the New Zealand healthcare system. It then describes a series of problems facing the system and proposed solutions. These include the need for team care, providing services

\section{Robin Gauld}

Department of Preventive and Social Medicine

University of Otago

Otago, New Zealand

Correspondence:

robin.gauld@otago.ac.nz

\section{Introduction}

In common with virtually all the world's high-income countries, New Zealand's public healthcare system is in an almost constant state of restructuring. The country had a reputation at one point, from the late 1980s to around 2000, of having the world's most restructured healthcare system. This was as successive governments of different political persuasions presided over wholesale changes to funding and planning mechanisms, creating much uncertainty and turmoil in the process, and divisions between policy makers, managers and health professionals. [1]

Since 2000, there has been relative calm, yet age old challenges with the system remain. These are the outcome of underlying institutional arrangements that have their origins in the Social Security Act 1938, which involved the world's first attempt to create a national health service along the lines of what the United Kingdom has today. [2] closer to patients' homes, focusing on a population of interest, connecting up the system, and engaging patients more closely in care design and delivery.

Abbreviations: DHS - District Health Board;

GP - General Practitioner; PHO - Primary Health Organisation.

Key words: healthcare system; restructuring; New Zealand; team care; population health; patient engagement.
At the time, the New Zealand government sought a series of objectives. These included universal access to services, with a focus on primary care and population health; an integrated service, with all health professionals working for one service and on the government payroll; and no barriers to care, regardless of income or location. These were ambitious goals and, in many ways, match with what policy makers around the globe seek today. Ironically, this includes New Zealand's policy makers over 75 years after their predecessors' efforts.

The problem for New Zealand lies in a political compromise reached with the medical profession in order to progress implementation of the 1938 legislation. This meant that public hospitals would be free of patient charges, with all employees, including health professionals, salaried and paid by the state. Doctors would be permitted to retain their private business status and ability to generate their own income. Thus, around $40 \%$ of hospital specialists are today in parallel private practice. General practice sits largely separately from the public hospital system, although GPs do receive around half their income from the government with patients directly charged at point of service. As a consequence, the government's integration goals have never been met, while various studies show that around $20 \%$ of New Zealanders report avoiding visiting a doctor when they feel a need to due to the cost barrier. [3,4] 
Restructuring in New Zealand today is evolutionary and incremental, focused on a series of concerns that hinge on the ability to traverse the historic institutional challenges and achieve the goals set down in 1938. This article describes a list of problems and proposed solutions. Some of these are encapsulated in current government policy; others, arguably, should be core policy concerns. The next section describes New Zealand's present healthcare system. This is followed by an account of the problems and solutions.

\section{New Zealand's healthcare system}

As noted elsewhere, New Zealand is often categorised along with other countries that have a 'national' health system. $[5,6]$ That said, it is a very loose version of this albeit with some of the characteristics. Central government is the primary funder, distributing tax funds directly into the public institutions via a Ministry of Health. The Ministry, in turn, funds 20 District Health Boards (DHBs). These are geographically-based local systems with responsibility for planning and funding the full spectrum of service for their population. The DHBs are funded on the basis of population, via a population-based funding formula. This is weighted for each region according to population and geographic characteristics, such as deprivation, ethnicity and rurality, meaning that there is around a $25 \%$ variation between the level of funds going to different DHBs. In theory, the funding formula is a proxy for need. DHBs own and fund public hospitals in their regions, and fund primary health organisations (PHOs) which, in turn, subsidise GP services. DHBs also fund various community-based services such as public health, disability support and mental health services. The incentive for DHBs is to focus on health and wellbeing and treatment in the community, rather than inpatient care, although there has tended to be a historic emphasis on hospitals.

Around $80 \%$ of total health expenditure is public. The remaining $20 \%$ of private expenditure is through patient co-payments to GPs, co-payments for prescribed medicines (which are heavily subsidised by government via Pharmac, the public drug-buying agency), and for private hospital and outpatient specialist services. These receive no government subsidy. Around a third of New Zealanders subscribe to private health insurance. Notably, private hospitals and specialists provide only non-urgent services. All major trauma services are publicly provided. Finally, an Accident Compensation Commission, which collects funds through a mix of workplace and other levies, funds patients with accidents and other injuries.
New Zealand's health system produces comparatively good outcomes and quality of care, and is considered to be relatively efficient at reasonable expenditure levels. [4] GDP expenditure on health in 2016 was 9.4\%, with per capita expenditure being USD3590 adjusted for purchasing power parity (compared to the OECD average of USD3740). [8] Yet government capacity to grow health expenditure remains restricted. Allocations to DHBs via the funding formula are routinely constrained. Indeed, annual funding increases tend to be at around the level of general inflation in the economy. DHBs, meanwhile, must live within their budgets, including accounting for cost increases. They have no other method for raising funding, other than income through treating patients from other regions (such as those who fall ill on holiday or with specific conditions requiring a transfer to a DHB with more specialised services). With the challenges of population change, ageing and multi-morbidity, ubiquitous to the world's health systems today, there is pressure to move the system in new directions, as described in the next section.

\section{Problems and solutions}

This section outlines five key problems and corresponding solutions.

\section{Team care}

In common with other countries across the Asia-Pacific and beyond, most health professionals in New Zealand work in a relatively traditional model and are trained, particularly in medicine, to work largely as sole practitioners. Team work tends to be within a profession, such as a medical specialty, and may only extend to collaborating around shift work and treatment of certain patients. Yet, in order to deliver highquality and safe care, professionals need increasingly to work in teams. [9] Demand for this is also being driven by the patient of the future: older, with multi-morbidity.

Team work means that every professional is part of a coordinated group of professionals, with specific training in team work, who then naturally work together. This has various potential aims and related benefits. Inside the hospital, multi-professional teams provide the care for every patient to ensure that agreed, best practice is routinely applied. They oversee one another's work, signaling when there have been lapses in standards of care an individual team member may have provided, or faults in the system for managing patients. Each team member sees themselves as a part of a system, not independent of it. The focus is on continual improvement, including methods for planning and evaluating intended improvements. Patients and families should also be integral to the team. 
The New Zealand official policy response, signalled in the 2016 New Zealand Health Strategy, is that team care is central to the future of healthcare delivery, and other organisations in New Zealand's health systems have also supported this. [10] In practice, there is limited training in team care at present. The initial solutions appear to be in a highlevel policy intention, with limited if any present centrallycoordinated support for developing team-based approaches to services delivery or training. Health professional training programmes, for instance, still predominantly work independently of one another, although there are some inter-professional training programmes which have been reasonably successful in terms of strengthening the team focus. Clearly, there is a demand for the universities and other professional educators to work collaboratively and focus on team care from the first day of training onwards. There is a demand for this, also, from amongst professional colleges and other workforce licensing bodies.

\section{Population focus}

Treatment provided to individuals is a key function of any healthcare system. Focusing on the population which services are provided to is equally if not more important than treatment services. This is as a strong population health focus and associated strategies is well known for potential to reduce demand on individual treatment services. Indeed, even countries such as the United States, where the incentives within the health system are weighted towards treatment services as providers are predominantly paid on a fee for service basis, are emphasising population health. $[11,12]$

New Zealand has been at considerable advantage in terms of population health. Since at least the 1980s, its funding model has been oriented towards populations, rather than individual services and practitioners, although, in practice, there are various exceptions to this. As noted above, the 20 DHBs are funded per population characteristics. Despite this history, various challenges to being fully focused on population health persist. These largely relate to the historic separation of primary and hospital-based care and different ways these parts of the system are funded and function. Public hospitals have also tended to dominate many discussions and funding decisions taken by DHBs, and are considered to be particularly important to an often very vocal public. Perceived threats to hospital services posed by the prospect of orienting more funding outside of hospitals and into population health are often vociferously voiced, with politicians, concerned with political impact, taking note. As such, the population focus and public health strategies and services have taken a back seat to individualised services. There has been inadequate central coordination or policy focus leading some to suggest that this is posing serious risks, with considerable downstream treatment costs.

\section{Providing services closer to home}

Following predictions around demographic and disease state changes in New Zealand, the location of care is seen to pose a significant barrier to providing timely and effective treatment into the future. The present concerns are that public hospitals will be under increasing pressure to provide for a growing number of patients with complex conditions, many of whom could be cared for in the community. These are patients with heart disease, respiratory conditions, diabetes and other diseases of ageing and lifestyle.

The response is to gradually shift services into community settings. This has been happening incrementally, but not necessarily in a planned and staged manner. In the 2000s, the government stimulated development of Primary Health Organisations (PHOs) throughout the country. PHOs feature a network of general practitioners (GPs) and other primary care providers who work with enrolled populations. [13] They provide additional services for some patients with chronic conditions, as well as health promotion and other population-based services. PHOs have not necessarily been proactive in-terms of keeping patients in community care settings, owing to the traditional model of GP services delivery which is via the sole independent private practice (although the average for New Zealand is around three GPs per practice).

The present government (elected in 2008) has commissioned various pilots for better supporting and developing community care. This includes a small number of Integrated Family Health Centres which are larger general practice and primary care centres with enough practitioners and patients to sustain a 24 hour, seven day a week operation. These centres provide additional diagnostic and treatment services that normally require a patient referral to hospital. Investments have also been made into a series of 'better, sooner, more convenient' sites. These draw together a range of care providers across a region to focus on better integration of services with a particular emphasis on primary care.

Since 2013, an 'alliance' has been required between every $\mathrm{PHO}$ and its respective DHB. Alliances are a mechanism for governing the 'whole of system' and for integrating services. Health professionals from primary care, hospitals and other services in the local DHB region work collaboratively. The 
aim is to work out which providers are best suited to care for specific patients, such as those with long-term chronic conditions, and to be proactive about this so that they do not require hospitalisation. The emphasis is naturally on primary care and development of coordinated and planned patient management, including the patient in such planning. Alliances have focused on a full spectrum of services that could be provided in primary care rather than hospital settings. Key to effective alliance working is strong clinical engagement and leadership. With this, it is possible to have conversations about the potential for different professionals to assume one another's work. This is particularly relevant in the case of hospital specialist services being shifted to GPs, for instance, or GP work being augmented by allied professionals and hospital specialist support. Alliance work is supported by government permission to shift funding from public hospitals into primary care settings, where clinically agreed. This may also mean that some specialist clinics might be run out of GP practices. [14]

\section{Connecting up services}

Related to the above, a considerable challenge in New Zealand, given the institutionalised and siloed nature of the healthcare system, is building a more connected health system. New Zealand has been at the forefront of information technology use in clinical care, with studies showing both early adoption of computers to support clinical practice as well as widespread utilitisation. $[15,16]$ Yet systems have largely supported existing work patterns and, historically, not been built to connect with one another. [17] The DHBs and PHOs have developed their own systems for their own purposes. Thus, capacity for a connected health system has been limited, along with potential to involve patients as both owners and users of health data.

Despite longstanding recognition of the need for coordination of health IT, only more recently has the government developed a concerted strategy for this (see http://healthitboard.health.govt.nz/news-events/news/nextphase-health-it-programme-announced accessed October 13, 2016). To be fair, this is the latest in a line of government efforts over the years. As with prior strategies, the present requires working within the constraints of legacy IT systems and the institutional arrangements described in the introduction of this article. In practical terms, this has posed significant barriers to sharing of patient and other clinical and management information. It has also meant professionals often work with very limited information, routinely relying on patients to inform them of medications they have been prescribed and their health history. This not only endangers patients and undermines efforts to improve care quality and health care systems; it is also inefficient. The current strategy has goals of creating separate information repositories in the North and South Islands of New Zealand, which the constituent DHBs, PHOs and other providers can utilise. In theory, services providers will share common information which will be updated in real time with each healthcare encounter. All New Zealanders have a unique National Health Index identification number, which facilitates this process. A separate goal is for all patients to have access to basic information in their electronic patient record, including capacity to see test results, appointments, prescriptions and so forth.

In practice, there is some way to go to achieve these goals. The South Island has managed to roll out an agreed data repository and IT system, developed by the five DHBs themselves, which links up various legacy systems. The North Island has, to date, been unable to traverse debates around system ownership or who the vendors should be. At the patient record level, general practices are gradually rolling out patient access as software and practice capacity permits. While incremental progress is being made, the outcome of fully connected services remains aspirational.

\section{Engaging patients}

The final challenge is around actively engaging patients in the care delivery process. Again, this is partly in response to the increasing prevalence of multi-morbidity as well as patients whose healthcare needs could benefit from more pro-active self-management. Of particular concern in the New Zealand context is patients of Maori and Pacific ethnicity, and lower socio-economic status, who tend to have higher healthcare needs, unequal access to services, and poorer health outcomes than the rest of the population. $[18,19]$

The official policy response, encapsulated in the New Zealand Health Strategy, is to build a health system, which is 'people powered'. In other words, a system in which patients are actively engaged at all levels of the system, from decision-making around services design and care delivery processes through to partnering with professionals around care plans so that there is clear and joint agreement on the responsibilities of both professionals and patients in care management. This, of course, hinges on investing in health literacy: improving patient capacity to comprehend health information, including how to access and use information both to improve their personal health and change lifestyle and other behaviours, and to comply with professional instructions. [20] An effective literacy strategy also requires 
standard clinical information agreed to by professionals and delivered in a written format that is easily digestable by patients. As yet, New Zealand is some way from this, while, as noted above, health IT has yet to deliver in a way that empowers patients and puts them in control of managing their personal health.

In a complex organisational context such as healthcare, to which New Zealand is not immune, navigating the system can be perplexing even for the most educated patients and their families. This is particularly so for those with multimorbidity, demanding the services of multiple different providers. This is where the services of health navigators can be useful, as demonstrated in some New Zealand sites and elsewhere. [21] To date, however, there has been limited official support for health navigators.

\section{Conclusion}

This brief article has described current challenges facing New Zealand's health system. The list of issues covered is not exhaustive. Indeed, other issues such as how to deal with workforce shortages in various areas, such as rural general practice and some hospital specialist services, are ongoing. [22] The interface between the public and private sectors in New Zealand also continues to raise questions, particularly around conflicts of interest between those working in both sectors and the fact that public hospitals treat patients with complications following private treatment.

The New Zealand government and publicly-funded providers such as the DHBs are pursuing solutions to each of the key problems identified in this article. As implied, there is a very high-level strategy providing the response for the decade from 2016. [10] However, as with all policy, there is a serious need for a detailed and concerted implementation plan. There is also a need for national coordination of the various developments across the $20 \mathrm{DHBs}$ and 30 PHOs. Without this, it will be difficult for successful innovations and service changes in one district to be translated into another for the simple reason that there is, otherwise, no mechanism for facilitating cross-sector learning. There is also, arguably, a need for specific support to nurture developments. This could be done in the way that the English NHS has commissioned 'vanguard' sites, providing seed funding with an intent to reorientate care in the various ways described in this article. [23] There is, of course, potential for comparing progress with the NHS vanguards, with their additional developmental support, with New Zealand developments, which are mostly occurring within existing resources. Perhaps this could be the topic of a future update on health system restructuring in New Zealand.

\section{References}

1. Gauld R. Revolving doors: New Zealand's health reforms - the saga continues. Wellington: Institute of Policy Studies and Health Services Research Centre; 2009.

2. Gauld R. Questions about New Zealand's health system in 2013, its 75th anniversary year. N Z Med J. 2013;126(1380):1-7.

3. Jatrana S, Crampton P. Primary health care in New Zealand: who has access? Health Policy. 2009;93(1):1-10.

4. Schoen C, Osborn R, Squires D, Doty M. Access, affordability, and insurance complexity are often worse in the United States compared to ten other countries. Health Aff. 2013;32(12):1-11.

5. Kuhlmann E, Blank RH, Bourgeault I, Wendt C, editors. The Palgrave International Handbook of Healthcare Policy and Governance. Basingstoke: Palgrave; 2015.

6. Blank RH, Burau V. Comparative health policy. 3rd ed. Houndmills: Palgrave Macmillan; 2010.

7. Penno E, Gauld R. How are New Zealand's District Health Boards funded and does it matter if we can't tell? N Z Med J. 2013; 126(1376):1-14.

8. OECD. OECD Health Data. Paris: OECD; 2016.

9. Friedman A, Hahn KA, Etz R, Rehwinkel-Morfe AM, Miller WL, Nutting PA, et al. A typology of primary care workforce innovations in the United States since 2000. Med Care. 2014; 52(2):101-11.

10. Minister of Health. New Zealand Health Strategy: Future Direction. Wellington: Ministry of Health; 2016.

11. Berwick DM, Nolan TW, Whittington J. The triple aim: care, health, and cost. Health Aff (Millwood). 2008;27(3):759-69.

12. Whittington JW, Nolan K, Lewis N, Torres T. Pursuing the triple aim: the first 7 years. Milbank Q. 2015;93(2):263-300.

13. Gauld R, Blank RH, Burgers J, Cohen AB, Dobrow M, Ikegami N, et al. The World Health Report 2008 - Primary Healthcare: How wide is the gap between its agenda and implementation in 12 high-income health systems? Healthc Policy. 2012;7(3):38-58.

14. Gauld R. What should governance for integrated care look like? New Zealand's alliances provide some pointers. Med J Aust. 2014; 201(3):s267-s8.

15. Jha AK, Doolan D, Grandt D, Scott T, Bates DW. The use of health information technology in seven nations. Inter J Med Inform. 2008;77:848-54.

16. Schoen C, Osborn R, Squires D, Doty M, Rasmussen P, Pierson R, et al. A survey of primary care doctors in ten countries shows progress in use of health information technology, less in other areas. Health Aff. 2012;31(12):2805-16.

17. Gauld R. One step forward, one step back? Restructuring, evolving policy and information technology and management in the New Zealand health sector. Government Information Quarterly. 2004; 21(2):125-42.

18. Gunasekara Fl, Carter K, McKenzie S. Income-related health inequalities in working age men and women in Australia and New Zealand. Aust N Z J Public Health. 2013;37(3): 211-7.

19. Baker MG, Barnard LT, Kvalsvig A, Verrall A, Zhang J, Keall M, et al. Increasing incidence of serious infectious diseases and inequalities in New Zealand: a national epidemiological study. The Lancet. 2012;379(9821):1112-9.

20. Sørensen K, Van den Broucke S, Fullam J, Doyle G, Pelikan J, Slonska Z, et al. Health literacy and public health: a systematic review and integration of definitions and models. BMC Public Health. 2012;12(1):1.

21. Doolan-Noble F, Smith D, Gauld R, Waters DL, Cooke A, Reriti H. Evolution of a health navigator model of care within a primary care setting: a case study. Aust Health Rev. 2013;37(4):523-8. 
22. Health Workforce New Zealand. The health of the health workforce. Wellington: Health Workforce New Zealand; 2014.

23. NHS England. New Care Models: Vanguards - Developing a Blueprint for the Future of NHS and Care Services. London: NHS England; 2015. 